J. Indones. Math. Soc.

Special Edition (2011), pp. 45-58.

\title{
LIVING WITH THE LABELING DISEASE FOR 25 YEARS
}

\author{
Joseph A. Gallian \\ Department of Mathematics and Statistics \\ University of Minnesota Duluth, Duluth, MN 55812, USA
}

\begin{abstract}
In this article I trace my involvement with graph labeling for the past 25 years. I provide some statistical information about the growth in interest in graph labeling and some open problems that I believe are accessible.

Key words: Graph labeling, graceful graphs, harmonious graphs.
\end{abstract}

2000 Mathematics Subject Classification: 01A05, 05C78

Received: 09-08-2011, revised: 09-09-2011, accepted: 04-12-2012. 